\title{
El método mixto: una aproximación metodológica a través de la campaña a las municipales de Barcelona en Comú
}

\author{
Lucía García-Carretero \\ Universitat Pompeu Fabra \\ lucia.garcia@upf.edu \\ https://orcid.org/0000-0002-1414-3921
}

\section{The mixed method: a methodological approach through Barcelona en Comú's council election campaign}

\begin{abstract}
RESUMEN
El presente artículo analiza la comunicación electoral de la coalición Barcelona en Comú durante la campaña a las municipales de Barcelona de 2015. En concreto, se centra en el análisis de las estrategias comunicativas en Twitter del 8 al 22 de mayo de 2015 por parte de los partidos políticos Barcelona en Comú, Iniciativa per Catalunya Verds, Esquerra Unida i Alternativa, Podem, Procés Constituent y EQUO. Para ello, se han analizado un total de 1.253 tweets en torno a tres niveles de análisis basados en la triangulación metofológica

cualitativa cualtitativa. En primer lugar, el análisis a nivel macro mediante la técnica cuantitativa del análisis de redes sociales (SNA). En segundo lugar, el análisis micro a través de la técnica de análisis de contenido cualitativo. Por último, la aplicación de entrevistas en profundidad semi estructuradas a los encargados de la comunicación electoral de los partidos políticos. Los resultados muestran el papel central del partido Barcelona en Comú en relación al resto de partidos durante la campaña electoral. Metodológicamente, se reafirma la relevancia y necesidad del método mixto o triangulación para un análisis completo y en profundidad de la comunicación electoral en redes digitales como Twitter.
\end{abstract}

PALABRAS CLAVE

Triangulación metodológica, Twitter, Análisis de redes sociales, Análisis de contenido, Entrevistas en profundidad, Comunicación electoral, Barcelona en Comú

\section{ABSTRACT}

This paper analyses the political communication of Barcelona en Comú electoral coalition during Barcelona 2015 council election. That is, the analysis of communication strategies on Twitter from Barcelona en Comú, Iniciativa per Catalunya Verds, Esquerra Unida i Alternativa, Podem, Procés Constituent and EQUO during 8th-22nd May 2015. For this purpose, 1,253 tweets have been analysed through a mix-method approach organized on three levels of analysis. Frist, the quantitative method based on Social Network Analysis has been used. Secondly, a content analysis has been applied. Finally, we used semi-structured in-depth interviews to ask the community managers of the six political parties. The results allow us to concluded that Barcelona en Comú political party centralised the electoral communication. Also, this paper reaffirms the need to use mix-method approach for a complete analysis of the electoral communication in digital tools.

\section{KEY WORKS}

Methodological triangulation, Twitter, Social network analysis, Content analysis, In-deep interview, Electoral communication, Barcelona en Comú 


\section{Introducción}

Barcelona en Comú (previamente Guanyem Barcelona) surge en junio de 2014 como partido político y gana las elecciones municipales de Barcelona en mayo de 2015. Un año después de su aparición, este movimiento-partido (della Porta, Fernández, Kouki y Mosca, 2017), junto a otras 5 organizaciones políticas del eje izquierda, formó la coalición electoral Barcelona en Comú. La autodenominada confluencia fue constituida con la participación de Barcelona en Comú (Guanyem, BeC), Iniciativa per Catalunya Verds (ICV) y Esquerra Unida i Alternativa (EUiA), Podem (P), EQUO (E) y Procés Constituent (PC).

Esta investigación analiza la comunicación en Twitter de Barcelona en Comú durante la campaña electoral a las municipales. Esto es, del 8 al 22 de mayo de 2015. El objetivo principal es profundizar en el uso de las redes digitales por parte de los nuevos partidos políticos, los cuales surgen directamente en el entorno digital, mediante un estudio de caso y la aplicación de la triangulación metodológica o el método mixto. El objetivo principal es analizar, mediante un estudio de caso (Yin, 2009), la estrategia de comunicación online de Barcelona en Comú, para comprender, en profundidad, la forma en que las nuevas fuerzas políticas, que aparecen en un entorno digital, utilizan las redes digitales. La coalición electoral Barcelona en Comú como caso de estudio (Yin, 2009) se encuentra vinculada a los movimientos sociales españoles que surgieron como consecuencia de la crisis económica (della Porta y Mattoni, 2014; della Porta y Pavan, 2017; Casero et al., 2017; Pavan, 2017), por ejemplo la Plataforma de Afectados por la Hipoteca (La PAH) o el movimiento de los Indignados o 15-M.

Estos movimientos sociales, a los que los autores se refieren como movimientos contra la austeridad (della Porta y Mattoni, 2014), introdujeron nuevo lenguaje y de acciones alternativas, tanto en el espacio físico como en el digital (Sampedro y Sánchez-Duarte, 2011; Flesher y Montañés, 2014; Casero et al, 2017). Asimismo impulsaron la oportunidad política para nuevos partidos (Mosca, 2014) como es el caso de Barcelona en Comú iniciando el ciclo político conocido como 'las ciudades del cambio'. El movimiento $15-M$ y La PAH, entre otros ejemplos, cuestionaron el consenso político y social establecido hasta ese momento a través de la cultura de la transición (della Porta et al., 2017).

Como consecuencia, el proceso de institucionalización de movimientos sociales en los últimos años ha tenido lugar acompañado de procesos, a priori, de democratización a lo largo del mundo (Doowon, 2006, in Piccio, 2016). Es el caso de diferentes partidos políticos de izquierdas surgidos en el marco de la Europa mediterránea como el Movimento 5 Stelle en Italia, Syriza en Grecia o Podemos en España (Auriemma et al., 2015; Poulakidakos y Veneti, 2016). Volviendo al caso español, Podemos en el ámbito nacional y otros partidos en el ámbito local y regional conocidos como "Los Comunes", surgidos en el contexto Post-15M (Sanz y Mateos, 2014), han capitalizado en términos electorales el descontento social de los últimos años. Es el caso de Ahora Madrid (Madrid), En Marea (Galicia) o Barcelona en Comú (Barcelona).

La comunicación política en general, y la comunicación electoral en particular, se encuentra ligada al concepto de mediatización de los políticos y de la política (Strömbäck, 2008; Couldry y Hepp, 2013; Landerer, 2013; Mazzoleni, 2017). La mediatización es entendida como un proceso de construcción sociocultural de la realidad mediante la comunicación (Couldry y Hepp, 2013) a través de los medios de masas como fuente de información política y electoral y a partir de la adopción de sus dinámicas por parte de partidos y candidatos (Mazzoleni y Schulz, 1999). Los medios tradicionales han pasado a ocupar un lugar central en las rutinas políticas, cuyo máximo exponente son las campañas electorales (Mazzoleni, 2008). La concepción teórica en torno a la mediatización se centra en la adaptación a las dinámicas y temporalidad de los medios de comunicación por parte de los partidos políticos con el fin de obtener mayor visibilidad (Strömback, 2008; Deacon y Stayer, 2014; Cammaerts, 2015). Por consiguiente, esta adaptación no puede ser entendida sin tener en cuenta la integración al proceso comunicativo de la tecnología, los cambios en el contexto económico y los cambios culturales (Landerer, 2013). De acuerdo con Daniel Hallin (2018), podemos referirnos al concepto de mediatización cuando, en el proceso comunicativo, la lógica de los medios impera sobre la lógica de los partidos e instituciones y la relega a un segundo plano.

Los medios sociales son espacios digitales sociales en los cuales el espacio cotidiano se encuentra mediado y en el cual las posibilidades de acción se encuentran estructuradas en un sistema jerárquico y diferenciado (Couldry y Hepp, 2017). Teóricamente, los partidos políticos en las redes digitales tienen la capacidad de difundir y gestionar su propio mensaje sin la intermediación de los medios y periodistas, no obstante la influencia de los medios de masas continúa manteniendo presencia en los medios sociales (Fenton y Barassi, 2011) superando el "mito de la horizontalidad" (Pavan, 2015) atribuido a los medios sociales. El proceso mediado de construcción de esta realidad política (Couldry, 2015) mediante el proceso comunicativo, tiene lugar simultáneamente en los medios de masas y en los medios sociales -el sistema híbrido de medios de Chadwick, 2013)- donde las líneas divisorias entre ambos se han desdibujado. Tanto los medios tradicionales como los nuevos medios tratan de influir en la representación social de la política y de los políticos y ambos pueden interaccionar y competir al mismo tiempo (Chadwick, 2013).

Los (nuevos) partidos políticos han interiorizado estrategias y dinámicas comunicativas que contemplan esta dicotomía mediática (Feenstra et al, 2017). Como consecuencia del sistema híbrido (Chadwick, 2013), se puede afirmar la aparición de la cuarta fase o post-moderna en las campañas electo- 
rales, o dicho de otra forma, la fase o campaña hipermedia (Lilleker, Tenscher y Štětka, 2015). Este tipo de campaña electoral se basa en una comunicación mediatizada (Römmele y Scheneidmesser, 2016), tanto en relación al uso de los medios digitales como en los medios de masas (Lilleker, Tenscher y Štětka, 2015). Así, encontramos dos tendencias comunicativas tanto en la organización de los partidos políticos como en su comunicación híbrida. Por un lado, los partidos políticos que se han adaptado a los cambios comunicativos propios del entorno digital y la hibridación, es decir, partidos más tradicionales; y por el otro, los partidos genuinamente híbridos en cuanto a comunicación se refiere (Chadwick, 2007). Es el caso de Barcelona en Comú, que surge directamente en el escenario digital cuando las redes ya se encuentran consolidadas como canal de comunicación política y electoral.

De acuerdo con lo mencionado, según los autores no hay una única lógica mediática en la campaña política hipermediada, ya que los actores políticos instrumentalizan y se adaptan a los diferentes medios (online y offline) y sus lógicas, en función las necesidades comunicativas concretas (Römmele y Scheneidmesser, 2016). La lógica de los medios se define como un proceso, conjunto de normas, códigos y formatos que influyen en la construcción de un mensaje para ser difundido a través de un medio de comunicación determinado (Altheide, 2004). Por lo tanto, los partidos políticos necesitan adaptar su mensaje a los criterios de los medios para recibir una cobertura favorable (Feenstra et al., 2017) que les permita ser percibidos de una forma concreta ante el electorado. De acuerdo con la lógica de los medios en la red, más allá del tipo de medio digital, los partidos se ven obligados a adaptar el mensaje (Klinger y Svensson, 2015), cuestionando la no hipermediación de las redes digitales, en línea con la afirmación de McLuhan (1987) de que el medio es el mensaje. De acuerdo con Guillermo López-García y José María Pavía (2018), la presente investigación forma parte del enfoque teórico en el que se considera el papel desempeñado por los medios en la comunicación política como central e inevitable. Así,

Such is the case with the Medium Theory (McLuhan, 1964) or the perspective of media logic (Altheide \& Snow, 1979). Later, enhanced by the emergence of the agenda-setting theory and its subsequently huge influence. All these approaches can be grouped around the concept of mediatisation (Schulz, 2004; Strömback, 2008), understood as the capacity of the media to set the scene and influence the manner in which other social institutions operate in the public sphere (2018, p.4).

Con el fin de profundizar en el análisis de la comunicación electoral en Twitter de Barcelona en Comú, este artículo contempla tres niveles de análisis de acuerdo con tres tipos de aproximaciones metodológicas, centrándonos en la triangulación o método mixto. La primera fase, relativa al análisis del comportamiento en la red de la coalición electoral Barce- lona en Comú, mediante el análisis de redes sociales (SNA). En segundo lugar, el análisis del mensaje difundido por Barcelona en Comú en Twitter, para lo cual el método seleccionado es el análisis de contenido (AC). Y por último, la consecución de entrevistas semi estructuradas en profundidad a los encargados de las estrategias comunicativas electorales en el seno de los partidos políticos de la confluencia, con el fin de contrastar los resultados de sus esfuerzos (SNA y AC) con su diseño y ejecución.

\section{Objetivos y metodología: triangulación cuantitativa-cualitativa}

Barcelona en Comú es un estudio de caso, por lo tanto, en esta investigación se asume que es ejemplo representativo (Yin, 2009) de los partidos-movimiento contra la austeridad en Europa y el mundo occidental (della Porta, et al., 2017) y de partidos genuinamente híbridos (Chadwick, 2007). Mediante el estudio de caso, podemos aproximarnos a la investigación de un evento, programa, actividad o, en nuestro caso, una coalición electoral concreta en un periodo de tiempo determinado (Creswell, 2009). Mediante el estudio de caso, podemos centrarnos en el proceso y efectos de un fenómeno (Kohn, 1997). Así, esta aproximaición "is an in-depth explanation from multiple perspectives of the complexity and uniqueness of a particular project, policy, institution, program or system in "real life" context" (Simons, 2009, p.21).

Asimismo, se basa en el método mixto (Edwards, 2010) o triangulación metodológica (Bellotti, 2015) ya que se considera imprescindible un enfoque cuantitativo-cualitativo para profundizar e investigar de forma completa y precisa la comunicación electoral en Twitter de Barcelona en Comú (Denzin, 1978; Webb, Campbell, Schwartz y Sechrest, 1966; Golafshani, 2003). Esto es, diferentes formas de aproximación o análisis para los mismos datos y el mismo fenómeno (Mitchell, 1986). De acuerdo con Wendy Olsen (2004), el método mixto proporciona diversos puntos de vista en un mismo análisis contribuyendo a una investigación completa y en profundidad.

En el nivel macro de investigación, el análisis de redes sociales, no solo redes sociales digitales, es una oportunidad para la triangulación metodológica ya que, debido a su interés por la forma o estructura de una red (Edwards, 2010), requiere del análisis de contenido cualitativo para completar el estudio a un nivel micro, es decir, profundizar en información más sensible (Edwards y Crossley, 2009). En base a Nick Crossley y Emma Edwards,

Our argument for mixing methods rests upon an ontological premise; namely, Bhasker's (1979) argument that social reality, though dependent upon actions, perceptions and conceptions of actors, exists independently of the perceptions, conceptions and research sociolo- 
gists. Social worlds exist to analyse them, and whilst the sociological gaze may impose particular perspectives upon and inform interventions within them, the aim of sociology is to explore and understand those worlds as independently existing domains (2016, p.3).

Por lo tanto, utilizamos el análisis de redes sociales (SNA) para los tweets difundidos por los seis partidos políticos que forman la coalición electoral Barcelona en Comú. En línea con la afirmación de Elisa Bellotti (2015), el SNA permite observar la red formada por diferentes actores, como es el caso de los partidos políticos, y las relaciones significativas entre ellos en un entorno red contextualizado en el seno de la campaña electoral. Analizamos 1.253 tweets difundidos a través de las cuentas oficiales de los seis partidos políticos: Barcelona en Comú (ळbcnencomu), Iniciativa per Catalunya Verds (ळiniciativaBCN), Esquerra Unida i Alternativa (aEUiABCN), Podem (aPodem_BCN), Procés Constituyente (apconstituentBCN) y EQUO (đEquobcn). Los objetivos del primer nivel macro de análisis son:

- 01. Analizar el flujo de comunicación y la relación entre los seis partidos políticos de la confluencia en Twitter durante la campaña electoral.

- 02. Estudiar la comunicación multidireccional entre los seis partidos políticos y los usuarios/ciudadanos a través de las respuestas en los tweets.

- 03. Identificar los temas electorales dominantes propuestos por los partidos políticos a través de los hashtags usados en Twitter.

En segundo lugar, se ha procedido a la aplicación del análisis de contenido cualitativo a los tweets de la coalición (Bardin,
2002; Colle, 2011; Krippendorff, 2013). A través de este método cualitativo, estudiamos el mensaje difundido no solo por las cuentas oficiales de Twitter de los seis partidos políticos de la coalición electoral, sino también por varias cuentas de candi-

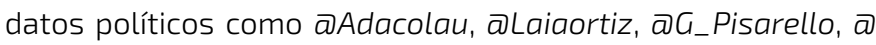
Janetsanz y aJaumeasens, y uno de los miembros de la comisión de comunicación y del Movimiento de Liberación Gráfica de Barcelona (a3eses) ya que, según los resultados del SNA realizado previamente, se trata de un actor político relevante a la hora de fijar el mensaje electoral. Los objetivos del segundo nivel de investigación son:

- 04. Discernir la estrategia de comunicación electoral de acuerdo con el mensaje difundido. Es decir, averiguar el tipo de mensaje y el tema electoral difundido por parte de los partidos políticos durante la campaña y su concordancia con los hashtags seleccionados.

- 05. Analizar el uso de Twitter realizado por los partidos que constituyen Barcelona en Comú con el fin de averiguar en qué medida se aprovechan las posibilidades de Twitter como herramienta de comunicación electoral.

- 06. Profundizar en el tipo de conversación entre los seis partidos políticos y los usuarios de Twitter.

Finalmente, en el tercer nivel, utilizamos entrevistas en profundidad semi estructuradas con el fin de:

- $\quad$ 07. Profundizar en el diseño y ejecución de las estrategias comunicativas electorales de la coalición.

- $\quad$ 08. Comparar las conclusiones obtenidas por SNA y el AC con la información aportada por los propios partidos de Barcelona en Comú.

\begin{tabular}{|c|c|c|}
\hline $\begin{array}{l}\text { Características } \\
\text { estructurales }\end{array}$ & Definición & Resultados asociados \\
\hline \multicolumn{3}{|c|}{ Toda la red } \\
\hline Densidad & $\begin{array}{l}\text { El número de vínculos existentes dividido por } \\
\text { el número de vínculos posibles en una red. }\end{array}$ & $\begin{array}{l}\text { Una densidad alta es un caldo de cultivo para la } \\
\text { confianza y el intercambio generalizado, a costa de } \\
\text { información redundante (Coleman, 1988). }\end{array}$ \\
\hline Reciprocidad & $\begin{array}{l}\text { La medida en que un vínculo de A a B coin- } \\
\text { cide con el vínculo de } B \text { a } A \text {. }\end{array}$ & $\begin{array}{l}\text { Valores altos de reciprocidad altos indican una relación } \\
\text { simétrica entre nodos. Valores de reciprocidad bajos } \\
\text { indican desequilibrio y que se trata de una red jerárquica. }\end{array}$ \\
\hline Transitividad & $\begin{array}{l}\text { La medida en que los extremos/relaciones } \\
\text { de una red están cerrados }\end{array}$ & $\begin{array}{l}\text { La alta transitividad sugiere una tendencia de los indivi- } \\
\text { duos a que sus lazos se conozcan con el tiempo, entre sí, } \\
\text { y se homogeneicen. }\end{array}$ \\
\hline \multicolumn{3}{|c|}{ Posición del nodo en la red } \\
\hline $\begin{array}{l}\text { Grado de } \\
\text { centralidad }\end{array}$ & $\begin{array}{l}\text { El número de conexiones directas a otros } \\
\text { nodos que posee un nodo concreto }\end{array}$ & $\begin{array}{l}\text { Un grado alto significa mayor acceso a los flujos de la } \\
\text { red (Freeman, 1979). }\end{array}$ \\
\hline $\begin{array}{l}\text { Centralidad de } \\
\text { intermediación }\end{array}$ & $\begin{array}{l}\text { El número de rutas más cortas que conectan } \\
\text { otros nodos en una red que pasan a través } \\
\text { de ese nodo. }\end{array}$ & $\begin{array}{l}\text { Se refiere a la alta entrelazabilidad significa un rápido } \\
\text { acceso y control sobre los flujos de red (Freeman, 1979). }\end{array}$ \\
\hline $\begin{array}{l}\text { Centralidad de } \\
\text { vector propio }\end{array}$ & $\begin{array}{l}\text { Determinado tanto por el número de cone- } \\
\text { xiones directas como por la calidad de sus } \\
\text { contactos. }\end{array}$ & $\begin{array}{l}\text { Cómo se refleja el nodo en la red y quién está vinculado } \\
\text { al mismo (Bonacich, 1987) }\end{array}$ \\
\hline $\begin{array}{l}\text { Centralidad de } \\
\text { cercanía }\end{array}$ & $\begin{array}{l}\text { El promedio de pasos para acceder a todos } \\
\text { los demás nodos de una red }\end{array}$ & Acceso rápido a los flujos de la red (Freeman, 1979) \\
\hline
\end{tabular}

Tabla 1. Características del SNA (Kane et al, 2014; en Pérez-Altable, 2016: 118). 


\subsection{Análisis de redes sociales (SNA)}

Las redes sociales (digitales y tradicionales) permiten entender el sistema social porque se centran en las diferentes relaciones entre los actores que construyeron este sistema (Borgatti, Everet y Johnson, 2013). Son fenómenos empíricos de patrones de relaciones (Bellotti, 2015) en el mundo digital y en la vida real (Bellotti, 2015; Borgatti et al., 2013). Las relaciones sociales tienen lugar en un entorno cultural concreto y delimitado, con características contextuales concretas y redes sociales específicas (Bellotti, 2015). En el caso de internet y las redes digitales, las conversaciones entre usuarios o el intercambio de información (comunicación multidireccional) se representa mediante hilos en el SNA (Aragón, Gómez, García y Kaltenbrunner, 2017), a su vez basado en la ciencia de redes y la teoría de grafos (Bellotti, 2015). Así, esta investigación concibe la red social como un todo en base al SNA (whole network) y la posición de cada nodo o actor en esta red (Kane et al, 2014). La tabla 1 ilustra las características en las que se centra el SNA de este trabajo.

La representación de SNA se lleva a cabo mediante gráficos donde los actores o nodos -cuentas en Twitter de los seis partidos de la coalición y candidatos- son puntos o vértices y las relaciones o vínculos entre ellos se representan mediante flechas -en los casos en los que hay una dirección lógica- o mediante arcos -si la comunicación es multidireccional- (Borgatti et al., 2013). El espacio social de la red (tabla 2) está formado por diferentes actores (nodos) y el intercambio de comunicación entre ellos (enlaces o aristas). Los actores o nodos tienen sus propias características, los denominados atributos por los cuales es posible categorizar, definir y diferenciar cada nodo (Borgatti et al., 2013).

A su vez, la relación entre estos nodos o actores tienen, también, sus propias características (Borgatti et al., 2013). Por lo tanto, nos centramos en eventos relacionales (relational events), (Atkin, 1977) puesto que se trata de una relación entre nodos basada en los 15 días de la campaña electoral. Como muestra la tabla 3, nos referimos a una relación no permanente entre actores, con un inicio y un final. Los eventos relacionales están formados por interacciones y flujos y los flujos son resultados de las interacciones (Borgatti et al., 2013). El número de conexiones entre vértices, la representación de los actores políticos, se denomina grado. Según Stephen Borgatti (2005, basándose en Freeman, 1979), el grado de centralidad determina el número de conexiones en relación a un nodo concreto y en función de si recibe las conexiones (in-degree centrality) o parten de este nodo (out-degree centrality).

Vinculado al grado de centralidad de los nodos, se pueden diferenciar dos tipo de actores: los nodos programadores y los nodos movilizadores (Padovani y Pavan, 2016). Los programadores son los que, con motivo de su alto in-degree en una red concreta, establecen o fijan el mensaje, por ejemplo los temas de campaña. Los nodos movilizadores son aquellos que difunden este mensaje a través de enlaces y conexiones dado su alto valor de out-degre (Padovani y Pavan, 2016). Por consiguiente, para el análisis de Twitter, nos centramos en los retweets y las menciones que envía o recibe cada uno de los usuarios entendidos como interacción. Los nodos con un alto in-degree son los que reciben mayor cantidad de menciones y son retweeteados en mayor medida, mientras que, por el contrario, los que reflejan un alto out-degree realizan un alto número de retweets y menciones. A pesar de que una de las características principales que se le atribuyen a las redes digitales en el marco comunicativo es su capacidad para facilitar la comunicación multidireccional -el mito de la horizontalidad- las conversaciones generalmente no muestran reciprocidad (Pavan, 2015).

\subsection{Análisis de contenido}

La aplicación metodológica del análisis de contenido en el segundo nivel parte de la necesidad de hacer inferencias a partir del texto (Krippendorff, 2013). A través de esta técnica

\begin{tabular}{|l|l|l|l|}
\hline \multicolumn{3}{|c|}{$G(V, E)$} & \\
\hline $\begin{array}{l}\text { Vértices }(V) \\
\text { Conjunto de vértices }\end{array}$ & Actores/Nodos & Puntos & Flechas \\
\hline $\begin{array}{l}\text { Bordes (Edges, E) } \\
\text { Conjunto de bordes }\end{array}$ & $\begin{array}{l}\text { Líneas de flujo } \\
\text { flujo de comunicación) }\end{array}$ & Directa (lógica) & Arcos \\
\cline { 3 - 4 }
\end{tabular}

Tabla 2. Teoría de grafos y SNA. Elaboración propia, basado en Borgatti et al. (2013).

\begin{tabular}{|c|c|}
\hline \multirow{3}{*}{$\begin{array}{l}\text { Estados relacionales } \\
\text { Relaciones permanentes }\end{array}$} & $\begin{array}{l}\text { Semejanza: fenómenos relacionales no sociales que pueden ser tratados como si lo fueran } \\
\text { desde el punto de vista metodológico (p. e. localización). }\end{array}$ \\
\hline & $\begin{array}{l}\text { Roles relacionales: son las relaciones humanas más permanentes en el tiempo (p. e. relación } \\
\text { madre-hija). }\end{array}$ \\
\hline & Relaciones cognitivas: pensamientos y sentimientos que unas personas hacia otras. \\
\hline \multirow{2}{*}{$\begin{array}{l}\text { Eventos relacionales } \\
\text { Relaciones no permanentes }\end{array}$} & Interactiones: comportamientos entre nodos que pueden ser observados por terceros nodos. \\
\hline & $\begin{array}{l}\text { Flujos: resultados y forma de las interacciones que forman un medio determinado para que } \\
\text { estas se produzcan (actitudes, normas, creencias). }\end{array}$ \\
\hline
\end{tabular}

Tabla 3. Estados relacionales y eventos relacionales. Elaboración propia, basado en Borgatti et al. (2013). 
basada en la descripción objetiva y sistemática del contenido de una comunicación (Berelson, 1971), los investigadores pueden inferir sobre el hablante, el receptor y el mensaje (Colle, 2011). Su carácter flexible lo convierte en un método de investigación aplicable a diferentes tipos de comunicaciones (Berelson, 1971). Ello siempre y cuando sea objetivo, estandarizado y mecánico (López-Noguero, 2002). El análisis temático (Bardin, 2002) es relevante para conocer los temas de campaña en Twitter y el marco o frame de esos temas (Goffman, 1986). El enfoque constructivista entiende que los conceptos adquieren sentido cuando alguien -los partidos políticos- los sitúan en un contexto o frame determinado (Van Gorp, 2010). Los estudios de comunicación política y electoral utilizan el análisis de los frames de diversas formas (Gitlin, 1980; Entman, 2004; Lakoff, 2004). Son particularmente relevantes las obras que se refieren a marcos de acción colectiva que organizan la experiencia y guían la acción electoral y política (Benford y Snow, 2000). En este sentido, el presente artículo busca definir cómo Barcelona en Comú relaciona y sitúa sus principales temas de campaña y mensajes electorales, la causa de los problemas que se plantean, las consecuencias de estas situaciones y las soluciones en términos de programa electoral (Entman, 2004).

Las categorías de análisis, están relacionadas con los actos ilocucionarios del habla (tabla 4) (Searle, 1976; Austin, 2003), la participación digital (Lobera, 2010) (tabla 5), los actores políticos (Figura 1), las posibilidades de Twitter y la clasificación de los temas diseminados por los partidos políticos.

En primer lugar, para averiguar la intencionalidad en la comunicación de los partidos políticos, se emplean los actos de habla de Austin (2003) y Searle (1976). Los actos ilocucionarios engloban las categorías de actos directivos, actos de comisivos, actos expresivos, actos de declarativos y actos asertivos. Sin embargo, de acuerdo con Searle (1976), cada expresión tiene una fuerza ilocucionaria, pero no necesariamente tiene contenido proposicional. Además, los verbos no son el único signo de fuerza ilocucionaria (Alarcón, 2008) y cabe la posibilidad de que algunos de los tweets de la campaña no contengan un verbo, debido a la limitación de espacio en 140 caracteres. ${ }^{1}$

La clasificación de Josep Lobera (2010) es relevante para pro-

\begin{tabular}{|l|l|}
\hline \multicolumn{2}{|c|}{ Actos del habla } \\
\hline Directivos & $\begin{array}{l}\text { Intentar que el receptor lleve a cabo una } \\
\text { acción concreta }\end{array}$ \\
\hline Comisivos & $\begin{array}{l}\text { Comprometer al hablante en un acción } \\
\text { futura }\end{array}$ \\
\hline Expresivos & $\begin{array}{l}\text { Expresar el estado psicológico del } \\
\text { hablante }\end{array}$ \\
\hline Declarativos & $\begin{array}{l}\text { Modificar una situación presente } \\
\text { generando/imaginando una nueva }\end{array}$ \\
\hline Asertivos & $\begin{array}{l}\text { Comprometer al hablante con la verdad } \\
\text { expresada }\end{array}$ \\
\hline
\end{tabular}

Tabla 4. Actos del habla (Searle, 1976; Austin, 2003).

\begin{tabular}{|l|l|}
\hline \multicolumn{2}{|c|}{ Categorías de participación digital } \\
\hline Información & Acceso a la información. \\
\hline Comunicación & Intercambio de información. \\
\hline Deliberación & $\begin{array}{l}\text { Procesos de examen, evaluación, } \\
\text { reflexión, debate, etc. }\end{array}$ \\
\hline $\begin{array}{l}\text { Consulta o toma } \\
\text { de decisiones }\end{array}$ & $\begin{array}{l}\text { Formas para conocer las opiniones de } \\
\text { los ciudadanos }\end{array}$ \\
\hline Acción creativa & $\begin{array}{l}\text { Acciones colaborativas desde el } \\
\text { entorno digital }\end{array}$ \\
\hline
\end{tabular}

Tabla 5. Participación digital (Lobera, 2010).

fundizar en la participación digital. El autor contempla cinco tipos de participación digital, en función de su finalidad y el tipo de red social o herramienta online utilizada por los partidos políticos. No obstante, para nuestra investigación, el canal de comunicación es Twitter, por lo que clasificamos los tweets en relación con la información, la comunicación, la deliberación, la consulta o toma de decisiones y la acción creativa (Lobera, 2010) y no en función de la herramienta utilizada.

También analizamos las posibilidades de comunicación relacionadas con el uso de Twitter por parte de los seis partidos políticos en relación con las imágenes, videos o enlaces. Se han explorado algunas posibilidades de Twitter como, por ejemplo, el número de "me gusta" o "favoritos" (Fav), retweets (RT) y \#hashtags utilizados por los partidos políticos.

En relación a las respuestas, se analiza el tipo de diálogo, las conversaciones entre los partidos políticos de la confluencia y los usuarios/ciudadanos. El objetivo es averiguar si es una comunicación multidireccional entre los partidos y los ciudadanos durante la campaña electoral. En este sentido, varios autores han notado las limitaciones en el uso de las redes digitales como canal de comunicación multidireccional (Graham, Broersma, Hazelhoff y Van't Haar, 2013; Jungherr, 2015) ya que las estructuras de poder, estructuras económicas y estructuras políticas prevalecen en del espacio online (Lilleker, Koc-Michalska y Schweitzer, 2011). Para analizar las respuestas de los usuarios se incluyen las categorías partidos políticos/políticos, periodistas/medios de comunicación y usuarios/ciudadanos en función de quién responde. Esta clasificación está relacionada con la tesis de Wolton (1989) que sitúa como principales actores políticos legítimos a actores públicos como las instituciones o partidos, los medios de comunicación y periodistas y actores ciudadanos, individuos o grupos como asociaciones (Wolton, 1989).

Se incluye, asimismo, un grupo de categorías destinadas al análisis de las respuestas o conversaciones que surgen en Twitter a partir de la información difundida por los partidos políticos, basada en el trabajo realizado por, entre otros autores, Deen Freelon (2010) y ampliada por Guillermo López-García y Lidia Valera-Ordaz (2015). En estas conversaciones se explora, asimismo, si los usuarios introducen un tema diferente al del tweet (micro tema). De acuerdo con esta 


\begin{tabular}{|r|r|r|r|}
\hline \multicolumn{5}{|c|}{ Agentes politicos } \\
\hline Partidos politicos & Medios de comunicación & $\times$ Usuarios/ciudadanos & No \\
\hline \hline Partidos politicos & Medios de comunicación & $\times$ Usuarios/ciudadanos & No \\
\hline \hline Partidos politicos & $\times$ Medios de comunicación & $\times$ Usuarios/ciudadanos & No \\
\hline$\times$ Partidos politicos & $\times$ Medios de comunicación & $\times$ Usuarios/ciudadanos & No \\
\hline \hline Partidos politicos & Medios de comunicación & $\times$ Usuarios/ciudadanos & No \\
\hline
\end{tabular}

Figura 1. Actores políticos. Elaboración propia en base a Wolton (1989).

taxonomía (Freelon, 2010, López-García y Valera-Ordaz, 2015, Valera-Ordaz, 2018), existen tres modelos de conversaciones, por lo tanto, tres modelos de democracia. Así, encontramos:

1. Modelo liberal-individualista: enfatiza en la capacidad del individuo para hacer oír su voz través de espacios digitales.

- Monólogo: el hablante emite comentario sin la intención de discutir su punto de vista con otros usuarios

- Revelación personal: revelación de información personal.

- Exhibición personal: el hablante disemina y publicita su propio contenido.

2. Modelo comunitario: mantiene el foco en la capacidad de las nuevas tecnologías para fortalecer los vínculos entre las comunidades ideológicas preexistentes.

- Homofilia ideológica: el usuario expresa el grado de acuerdo o rechazo con el tweet publicado. Cuanto mayor es el grado de acuerdo entre los hablantes, mayor es la homofilia.

- Movilización: el usuario reafirma su intención de movilización política mediante la participación en actos físicos electorales, intención de voto, aportaciones económicas o mediante movilización a otros usuarios.

- Identificación comunitaria: el usuario se auto percibe como parte de la comunidad y el mensaje denota el sentimiento de pertenencia.

3. Modelo deliberativo: establece el foto en el potencial tecnológico para llevar a cabo un diálogo racional.

- Argumentación: opinión razonada, con la voluntad de argumentación detectable en presencia de adverbios causales.

- Reciprocidad: se centra en la observación de una respuesta a otro usuario.

- Libertad discursiva: el tipo de lenguaje empleado por los usuarios en sus respuestas.

\subsection{Entrevistas semiestructuradas}

El tercer nivel de análisis se centra en entrevistas en profundidad semi estructuradas (Ruiz-Olabuénaga, 2012). La entrevista es una metodología sistematizada y estandari- zada con un propósito específico, sujeta a la apariencia de una conversación normal (Kvale, 1996). Este método cualitativo resulta útil para obtener más información sobre situaciones o eventos que no se pueden observar de manera directa (Taylor y Bogdan, 1992). La entrevista semi estructurada mantiene un final abierto como consecuencia de un diálogo en profundidad (Morrow, 2005; O'Sullivan, 2005; Kvale, 2007). No obstante, es importante combinar las entrevistas con otro tipo de métodos de investigación, ya que depende directamente del discurso y voluntad del entrevistado (Taylor y Bogdan, 1992). La aplicación de esta metodología requiere un cierto nivel de información y conocimiento del tema y objeto de estudio (Wengraf, 2001; Kelly, 2010) que se ha obtenido con los dos pasos anteriores, el SNA y el AC. Las entrevistas semi estructuradas (Flick, 2004) se basan en un modelo donde las preguntas dependen de las características del entrevistado, según un punto de vista etnográfico y biográfico (Vallés, 2009). De esta forma, se obtiene información relevante, útil e importante relacionada con la dinámica comunicativa del caso de estudio Barcelona en Comú (Brennen, 2013), de manera colaborativa y activa (Fontana y Frey, 2005). Las entrevistas cualitativas se centran en el significado, el contexto, las relaciones y las experiencias del entrevistado (Pietkiewicz y Smith, 2014). Así, la aplicación metodológica se lleva a cabo en miembros/participantes en la comisión de comunicación de Barcelona en Comú durante el diseño y ejecución de la campaña a las municipales.

Esta conversación se registra mediante una estructura estandarizada (de Vaus, 2001). En nuestro estudio de caso, utilizamos un guión flexible que incluye preguntas básicas relacionadas con la campaña electoral y condicionadas por el contexto -social, político, económico y cultural- de Barcelona en Comú y de los entrevistados (Flick, 2004). El guión en torno al cual se estructura la conversación, resulta útil cuando el investigador sabe algo sobre el entrevistado y sobre el objeto de estudio a través de la investigación de campo (Taylor y Bogdan, 1992). Aunque el modelo semi estructurado permite al investigador redefinir las preguntas y ofrece libertad (Wimmer y Dominick, 1996), se basa en un cuestionario definido previamente (Agirreazkuenaga, 2012). La revisión metodológica de entrevistas semi estructuradas llevada a cabo por Hanna Kallio, Anna-Maija Pietilä, Martin Johnson y Mari Kangasniemi (2016) señala cinco fases esenciales dentro del proceso de la entrevista. La primera fase, con el fin de identificar la necesidad de la misma; en segundo lugar, la fase en la cual el investigador debe preparar el contexto con información previa sobre el tema o estudio de caso; la tercera fase se basa en la redacción de una guía o protocolo y el libro de codificación; en la cuarta, se preparan las preguntas preliminares; y finalmente, se establece cómo dar forma y presentar las respuestas y los resultados (Kallio et al, 2016). Para agrupar las unidades de análisis, las variables y las categorías creadas para estas entrevistas (Wimmer y Dominick, 2011), utilizamos el software Dataminer Pro con diferentes categorías y campos, que depende del tipo de pregunta (abierta o cerrada). El 


\begin{tabular}{|c|c|}
\hline $\begin{array}{c}\text { Grupo } 1 \\
\text { Información } \\
\text { general y } \\
\text { preguntas } \\
\text { descriptivas }\end{array}$ & $\begin{array}{l}\text { - Implicación y motivación personal en el } \\
\text { partido/confluencia } \\
\text { - Periodo de participación }\end{array}$ \\
\hline $\begin{array}{c}\text { Grupo } 2 \\
\text { Estructura } \\
\text { del grupo de } \\
\text { comunicación } \\
\text { y roles profe- } \\
\text { sionales }\end{array}$ & $\begin{array}{l}\text { - Estructura de la comisión de comuni- } \\
\text { cación } \\
\text { - Perfiles dentro del grupo } \\
\text { - Responsabilidad de cada rol y relación } \\
\text { entre los diferentes perfiles } \\
\text { - Dinámicas comunicativas durante la } \\
\text { campaña electoral } \\
\text { - Coordinación entre los grupos de comu- } \\
\text { nicación de los seis partidos }\end{array}$ \\
\hline $\begin{array}{c}\text { Grupo } 3 \\
\text { Herramientas } \\
\text { y canales de } \\
\text { comunicación } \\
\text { digital }\end{array}$ & $\begin{array}{l}\text { - Principal canal de comunicación } \\
\text { durante la campaña } \\
\text { - Relación con los medios de masas } \\
\text { - Posición de cada medio en relación a su } \\
\text { relevancia dentro de la campaña } \\
\text { - Tipos de herramientas (comunicación } \\
\text { interna y externa) } \\
\text { - Estrategia/protocolo específico para las } \\
\text { redes digitales } \\
\text { - Gestión de las redes digitales de los } \\
\text { partidos y candidatos } \\
\text { - Por qué seis cuentas en las redes digi- } \\
\text { tales en lugar de una de la coalición }\end{array}$ \\
\hline $\begin{array}{l}\text { Grupo } 4 \\
\text { Estrategias } \\
\text { comunicativas } \\
\text { El mensaje }\end{array}$ & $\begin{array}{l}\text { - Definición del mensaje } \\
\text { - Selección del mensaje } \\
\text { - Mensaje diferente para cada medio } \\
\text { - Coordinación del mensaje (homogenei- } \\
\text { dad) entre los seis partidos } \\
\text { - Mensaje de campaña institucional vs la } \\
\text { otra campaña }\end{array}$ \\
\hline $\begin{array}{c}\text { Grupo } 5 \\
\text { Respuestas } \\
\text { Comunicación } \\
\text { multidirec- } \\
\text { cional }\end{array}$ & $\begin{array}{l}\text { - Gestión de las respuestas } \\
\text { - Identificación de las respuestas (usua- } \\
\text { rios/ciudadanos + negativas/positivas) } \\
\text { - Cuentas personales/cuentas oficiales/ } \\
\text { cuentas de los candidatos } \\
\text { - Relevancia de las respuestas (temas/ } \\
\text { argumentos) } \\
\text { - Feedback }\end{array}$ \\
\hline
\end{tabular}

Tabla 6. Guión de las entrevistas semi estructuradas en profundidad. Elaboración propia.

cuestionario semi estructurado incluye cinco grupos de preguntas (tabla 6).

\section{Resultados}

\subsection{Primer nivel: SNA}

La aplicación del SNA, incluido en trabajos previos (García-Carretero y Pérez-Altable, 2017) en un marco de investigación más amplio muestra que el principal partido de la coalición en generar la información electoral en Twitter durante la campaña fue BeC. Desde la cuenta de Twitter de BeC se fija el mensaje electoral -nodo programador- mientras que los cinco partidos restantes -ICV, Podem, EUiA, Procés Constituent y EQUO- actúan como movilizadores, es decir, difundiendo la agenda propuesta por BeC. En este sentido, destacan particularmente los casos de EUIA y EQUO ya que, durante la campaña electoral, apenas participaron en Twitter desempeñando alguno de los dos roles presentados en el SNA. Por el contrario, ICV y BeC fueron los partidos que más explotaron el potencial bidireccional de Twitter. La reciprocidad (comunicativa) entre los nodos muestra valores bajos, por lo que podemos hablar de una red jerárquica organizada en torno a un nodo o actor central (Figura 2) y, por tanto, una distribución asimétrica del poder, donde BeC centraliza la comunicación electoral.

De acuerdo con la multidireccionalidad del total de tweets diseminados, BeC es el partido con mayor in-degree. Seguido por ICV, Podem, Procés Constituent y EUiA. Por su parte, EQUO no recibió ninguna mención durante la campaña en Twitter. En cuanto al out-degree, destaca el papel de ICV. Con mayor profundidad, las tablas 7 y 8 muestran el papel llevado a cabo por los partidos a la hora de fijar la agenda electoral. De acuerdo con la categorización de Elena Pavan (2015), entre los partidos que fijan los temas de campaña (programadores) destaca, una vez más, la comunicación en Twitter de Barcelona en Comú. No obstante, los resultados del SNA muestran la necesidad de incluir otros nodos en esta investigación así como profundizar en su mensaje. Es el caso de Ada Colau y otros candidatos de la confluencia. Asimismo, mediante el SNA se ha identificado

\begin{tabular}{|l|c|}
\hline \multicolumn{1}{|c|}{ Programadores } & In-degree \\
\hline @bcnencomu & 1263 \\
\hline @adacolau & 880 \\
\hline @g_pisarello & 132 \\
\hline @laiaortiz & 115 \\
\hline @misanchezgar & 65 \\
\hline @janetsanz & 64 \\
\hline @3eses & 61 \\
\hline
\end{tabular}

Tabla 7. Nodos programadores (García-Carretero y Pérez-Altable, 2017).

\begin{tabular}{|l|c|}
\hline \multicolumn{1}{|c|}{ Movilizadores } & Out-degree \\
\hline @iniciativabcn & 468 \\
\hline @bcnencomu & 439 \\
\hline @pconstituentbcn & 199 \\
\hline @misanchezgar & 186 \\
\hline @3eses & 108 \\
\hline @podem_bcn & 93 \\
\hline
\end{tabular}

Tabla 8. Nodos movilizadores (García-Carretero y Pérez-Altable, 2017). 


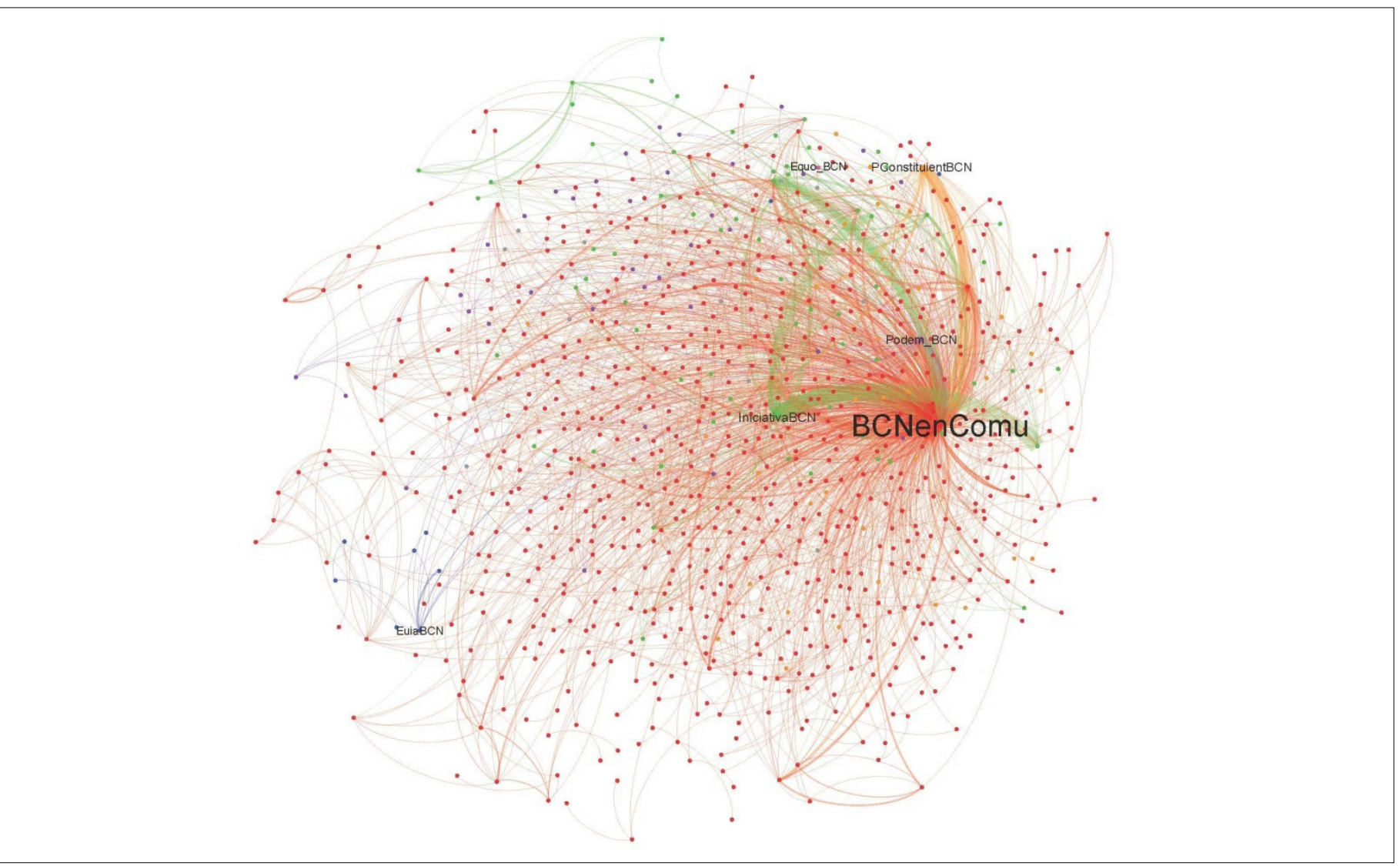

Figura 2. Actores comunicativos durante la campaña electoral (García-Carretero y Pérez-Altable, 2017).

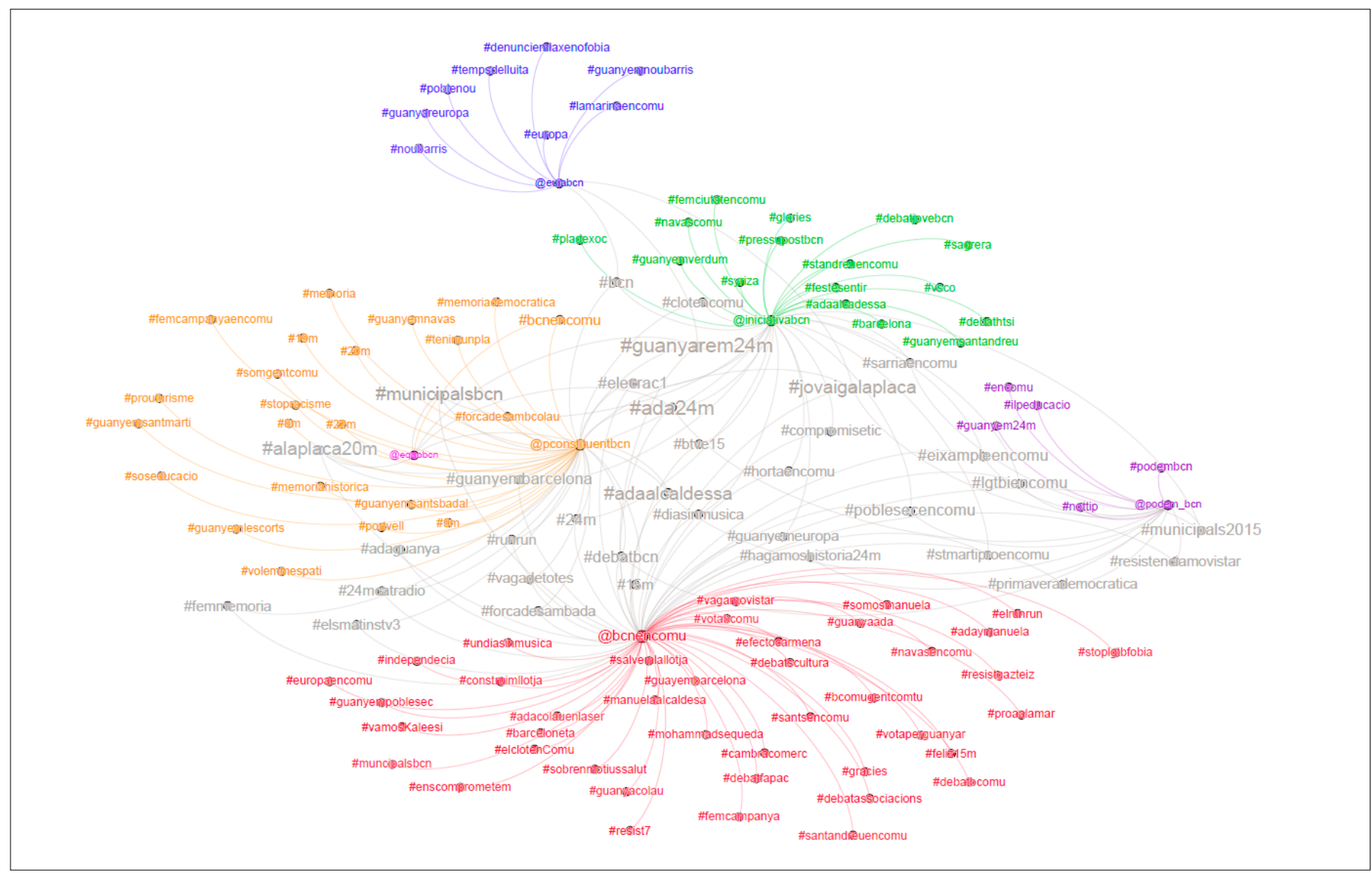

Figura 3. Distribución de los tweets de la confluencia (García-Carretero y Pérez-Altable, 2017). 
a uno de los miembros de la comisión de comunicación y del Movimiento de Liberación Gráfica de Barcelona relevante en el establecimiento de los temas de campaña (ळ3eses).

El total de 128 hashtags analizados (Figura 3) muestra la necesidad de llevar a cabo un análisis temático mediante otra metodología (AC) ya que los hashtags más comunes son transversales para todos los partidos y durante toda la campaña, es decir, no se refieren a un tema de campaña concreto. Entre los más relevantes, encontramos \#Adaalcaldessa, \#alaplaça20m, \#jovaigalaplaça y \#municipalsben.

\subsection{Segundo nivel: $\mathrm{CA}$}

La aplicación metodológica del análisis de contenido nos ha permitido profundizar en las estrategias comunicativas de la coalición electoral Barcelona en Comú en diferentes aspectos, tanto en relación al mensaje difundido por las cuentas en Twitter de los seis partidos, como en relación a el mensaje de candidatos y usuarios (García-Carretero y Díaz-Noci, 2018).

Así, se ha observado que entre los temas de campaña predomina la difusión de la agenda electoral -principalmente actos en el espacio físico y debates o entrevistas de los candidatos en televisión- dirigida a su público objetivo o posible electorado mediante los actos asertivos (Searle, 1976; Austin, 2003). Es decir, con la intención de implicar o comprometer a los usuarios o receptores a la participación de los mismos, ya sea acudiendo a estos actos o generando debate en torno a apariciones de los candidatos en televisión a través del uso de hashtags. Seguidamente, encontramos mensajes basados en activismo y participación ciudadana, desigualdades sociales propios de los movimiento-partidos (della porta et al., 2017)-y apelación al voto (Figura 4). Entendiendo el populismo como un estilo de comunicación política basado en la articulación de la hegemonía (Abts y Rummers, 2007; Moffit y Tormey, 2014; De Smet, 2016), el mensaje de la confluencia se encuadra en un frame basado en "la gente común" y el "bien común". Esto es, la lucha o articulación del nosotros contra ellos con el fin de recuperar el espacio público que pertenece a los vecinos y los barrios de Barcelona, ser la fuerza más votada como única posibilidad para el cambio real y esperanza de cambio mediante un programa electoral "desde abajo" (activismo) que permita combatir las desigualdades y dignificar la política y a los políticos. Este cambio en la política mediante la participación ciudadana y el activismo supone una ruptura con la distribución anterior de lo político, donde el poder pertenece a un grupo de privilegiados (los otros), entendido esta lucha de poder en términos de revolución democrática.

En cuanto al análisis temático de las cuentas de Twitter de los candidatos o políticos de Barcelona en Comú, se ha observado que la distribución de la selección temática en estas cuentas es similar a las cuentas de los partidos, por lo tanto, se sigue una estrategia comunicativa electoral coordinada en Twitter. No obstante, se ha observado variaciones en cuanto al tono o registro del mensaje, otra de las características del popu-

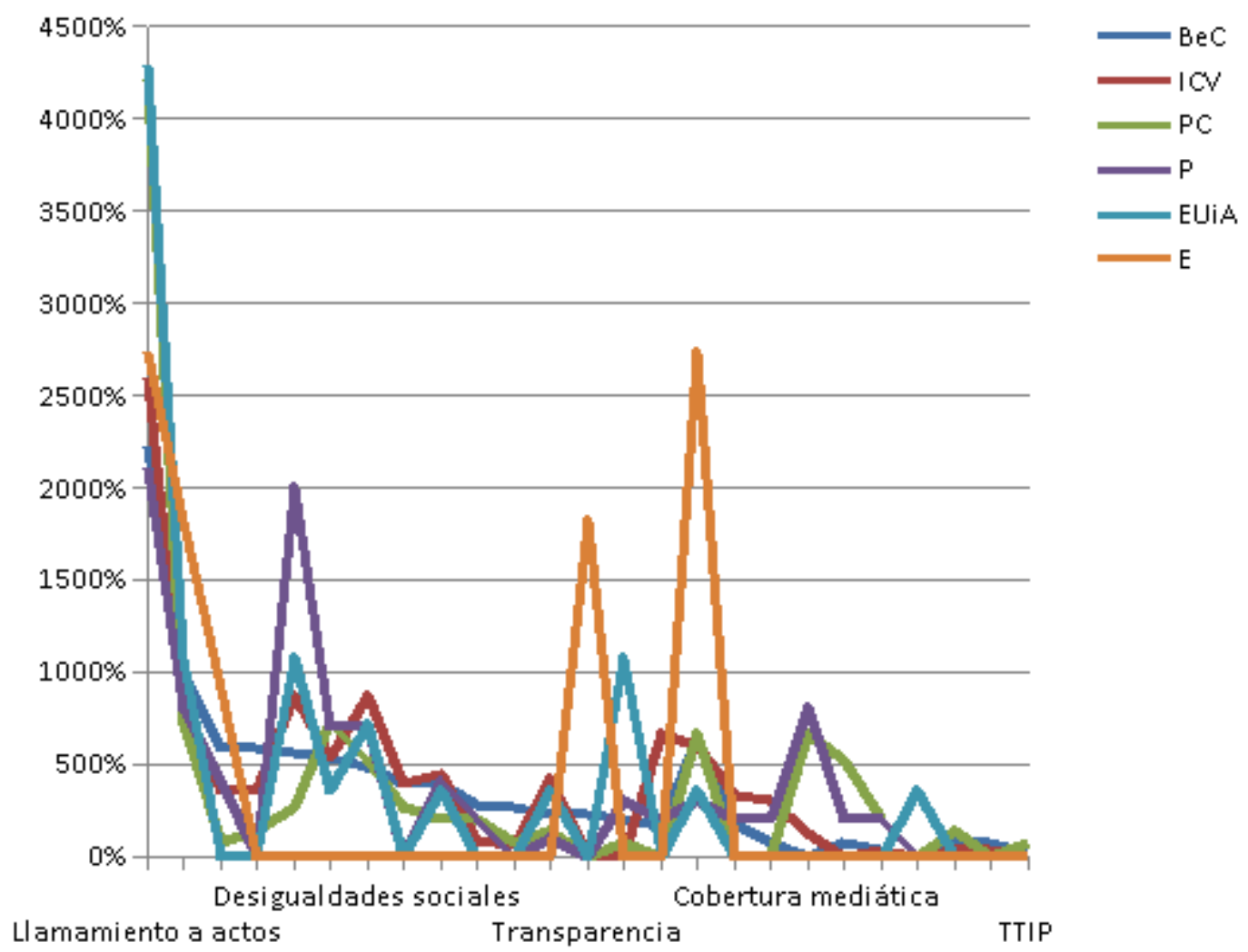

Figura 4. Distribución temas de campaña (García-Carretero y Díaz-Noci, 2018). 
lismo como estilo de comunicación política (Tudoroiu, 2014; Bracciale y Martella, 2017; Feenstra et al., 2017). Así, desde la cuenta aadacolau, la candidata a la alcaldía de Barcelona, mediante un registro más informal y personal, introduce los temas de campaña apelando a las emociones, mediante el storytelling y ejemplos basados en su propia experiencia como "gente común".

Los seis partidos políticos, en relación a las principales posibilidades de Twitter como herramienta digital, incluyen contenido audiovisual y enlaces a las páginas web o hub (Giansante, 2015) de los partidos políticos donde se amplía la información electoral y política (ver García-Carretero y Codina, 2018). Como se ha observado en el primer nivel de análisis (SNA), los hashtags son, en términos generales, transversales y no se relacionan con un único tema de campaña. No obstante, predomina la imagen sobre el video en un formato en el que, dadas las limitaciones textuales de Twitter, en actos o debates concretos se incluyen imágenes donde se amplía la información textual del mensaje.

Se ha observado que la principal finalidad de Twitter como herramienta digital es la comunicación o el intercambio de información (Lobera, 2010). Por el contrario, es significativamente negativo el uso de Twitter como herramienta de participación, consulta o toma de decisiones.

En este sentido, el análisis de las conversaciones con los usuarios en la red digital nos permite afirmar que el uso de la red digital como herramienta multidireccional es limitado. Según la categorización basada en tres modelos de democracia (López-García y Valera-Ordaz), el único partido político caracterizado con cierto grado deliberativo en sus conversaciones es Barcelona en Comú. No obstante, sin garantizar cierto grado argumentativo en las respuestas y con una limitada aportación de nuevos temas a la discusión. Además, se ha observado que los partidos políticos no intervienen significativamente en las conversaciones que surgen a partir de sus mensajes independientemente del tipo de comentario. Sin embargo, se ha observado la participación de miembros de la comisión de comunicación en las conversaciones desde sus cuentas personales sin identificarse, claramente, como miembros de Barcelona en Comú.

\subsection{Tercer nivel: entrevistas en profundidad}

La ejecución metodológica de las entrevistas en profundidad ha permitido establecer la causalidad de algunas de las dinámicas de Barcelona en Comú en Twitter así como conocer el funcionamiento interno de los grupos de comunicación de una coalición electoral formada por seis partidos políticos. Retomando el mito de la horizontalidad (Pavan, 2015), los resultados basados en una red jerárquica del SNA y la falta de participación en las conversaciones en Twitter como indica el AC (López-García y Valera-Ordaz), las entrevistas en profundi- zar permiten situar la falta de respuesta como una estrategia premeditada durante la campaña. A través de las entrevistas, se ha asegurado la estrategia de no intervención en las conversaciones de las cuentas de los partidos pero sí a través de los perfiles en Twitter de los miembros de la comisión de comunicación. El argumento se articula en torno a dos ejes. Dar respuesta a las dudas por parte de los miembros del grupo que contaban con más información respecto al tema objeto de debate y, así, dotar la conversación de un tono menos institucional al no intervenir los partidos (de ciudadano/usuario a ciudadano-usuario).

Cabe destacar, además, la finalidad atribuida a los perfiles oficiales por parte de los partidos políticos, lo cual condiciona tanto el mensaje como el tono del mismo. Así, encontramos dos tipos de campaña electoral y, por tanto, al menos dos usos diferentes de las redes digitales por parte de Barcelona en Comú. En primer lugar, la campaña oficial o institucional, analizada en esta investigación. En segundo lugar, una campaña más flexible, con un tono más dinámico, basada en el contenido audiovisual y el diseño gráfico, más propia del activismo fandom (Earl y Kimport, 2009) o del fandom político (Coleman, 2003; Erikson, 2008; Madore, 2009; Sandvoss, 2013).

Otro aspecto relevante es el diseño de la comunicación de la coalición durante la campaña articulada a través de los seis partidos políticos. La comisión de comunicación se organizaba como espacio abierto con dos perfiles diferenciados. En primer lugar, el grupo más permanente organizado por "meritocracia" es decir, en función de la especialidad comunicativa de cada miembro (redes, diseño, audiovisual, etc). En segundo lugar, un segundo grupo de apoyo que ejecutaba la comunicación. Las estrategias comunicativas electorales se llevaron a cabo por parte de cada partido, con traspaso o flujo de información continuo pero sin que hubiese un grupo unificado de los seis partidos. En relación a las cuentas de los candidatos, la gestión la llevaban a cabo los titulares de las cuentas aunque con apoyo del grupo de comunicación cuando, debido al momento concreto de la campaña, era necesario.

\section{Conclusiones}

La consolidación de las redes digitales como herramientas de comunicación política y electoral (Campos-Domínguez, 2017), así como la aparición de nuevos objetos de estudios en los que convergen dinámicas comunicativas tanto de movimientos sociales, como de partidos institucionalizados, muestra la necesidad de aproximarse a ellos desde diferentes perspectivas para su completo entendimiento y análisis. El empleo de las redes digitales por parte de los partidos políticos plantea numerosas preguntas de investigación en cuanto a su uso y/o el mensaje difundido en ellas pero, sobre todo, muestra un interés incipiente por el uso de las redes digitales como canal de comunicación bidireccional. 
La investigación realizada mediante la triangulación metodológica o método mixto (Bellotti, 2015) -y su organización en tres niveles de análisis - reafirma la complejidad comunicativa de la red y la necesidad de abordar su análisis mediante diferentes métodos que permiten la observación completa de la misma (Denzin, 1978; Webb, Campbell, Schwartz y Sechrest, 1966; Golafshani, 2003).

Por su parte, la metodología cuantitativa, en un nivel macro de análisis, resulta útil para explorar los patrones de conexiones sociales y conocer los sus sesgos de manera estadística (Bellotti, 2010; Crossley y Edwards, 2016). De esta forma, el análisis de redes sociales (SNA) ha contribuido a conocer el comportamiento de los partidos políticos durante la campaña electoral en la red, conocer el contexto de la campaña electoral, los actores políticos dominantes, quién establece la agenda y quién la difunde. Al mismo tiempo, muestra limitaciones sobre cómo gestionan la comunicación electoral los actores políticos, cuál es el mensaje o las causas de este comportamiento en la red.

La aproximación cualitativa permite identificar y profundizar en estos patrones de comportamiento y ofrece detalles más concretos en un nivel micro de análisis (Bellotti, 2010; Crossley y Edwards, 2016). Por ello, el análisis de contenido nos ha permitido profundizar tanto en el qué como en el cómo de las estrategias comunicativas además de en el contexto de este mensaje. Sin embargo, sin las entrevistas no habríamos obtenido información de acuerdo con si los datos observados y los resultados forman parte de la estrategia coordina de la coalición electoral Barcelona en Comú o son consecuencia de otros factores no diseñados para la campaña. Todo ello, reafirma la tesis de partida de esta investigación en cuanto a la relevancia del método mixto para una investigación completa y en profundidad.

Se considera, que lo anteriormente expuesto, da lugar a que esta investigación reitere la necesidad de aproximarnos a la investigación de redes digitales mediante la triangulación metodológica o el mixed-method approach (Edwards, 2010), combinando técnicas cuantitativas y cualitativas y así obtener la mayor información de análisis posible sobre el mismo objeto de estudio.

\section{Nota}

Este trabajo forma parte del proyecto "Creación y contenido interactivo en la comunicación de información audiovisual: audiencias, diseño, sistemas y formatos". CS02015-64955-C42-R (MINECO/FEDER), Ministerio de Economía y Competitividad (España).

\section{Notas a pie de página}

1. En la actualidad, desde septiembre de 2017, la limitación de caracteres en Twitter es de 280. Durante el periodo de análisis, la limitación era de 140 caracteres.

\section{Referencias}

Abts, K., y Rummers, S. (2007). Populism versus Democracy. Political Studies, 55(2), 405-424.

Agirreazkuenaga, I. (2012). Euskadi Irratiko (EITB) eta Radio nan Gàidheal-go (BBC ALBA) kazetarien profil eta jarreren alderaketa (Tesis Doctoral). Universidad del País Vasco-Euskal Herriko Unibertsitatea, Bilbao, España.

Alarcón, M. A. (2008). Austin y Searle: la relación entre verbos y actos ilocucionarios. Literatura y lingüística, (19), 235-250.

Altheide, D. L. (2004). Media Logic and Political Communication. Political Communication, 21(3), pp. 293-296.

Aragón, P., Gómez, V., García, D., y Kaltenbrunner, A. (2017). Generative models of online discussion threads: state of the art and research challenges. Journal of Internet Services and Applications, 8(15), pp. 1-17.

Atkin, R. H. (1977). Combinational Connectives in Social Systems. Basel: Birkhanser.

Auriemma, M., Esposito, E., ladiciccio, E., Marrazzo, F., Polimene, A., Punziano, G., y Sarnelli, C. (2015). Euroscetticismo a 5 Stelle: Stili comunicativi e online text data nel caso delle elezioni europee 2014. Sociologia della comunicazione, (49), 36-54.

Austin, J. L. (2003). Cómo hacer cosas con palabras. Barcelona: Paidós.

Bardin, L. (2002). Análisis de contenido. Madrid: Akal.

Bellotti, E. (2010). Comment on Nick Crossley/1. Sociologica, (1), pp 1-8. DOI: $10.2383 / 32050$

Bellotti, E. (2015). Qualitative Networks. Mixed Methods in Sociological Research. New York: Routledge.

Benford, R. D., y Snow, D. A. (2000). Framing Processes and Social Movements: An Overview and Assessment. Annual Review of Sociology, 26, 611-639.

Berelson, B. (1971). Content Analysis in Communication Research. New York: Hafner.

Borgatti, S. P. (2005). Centrality and network flow. Social Networks, (27), 55-71.

Borgatti, S. P.; Everet, M. G., y Johnson, J. C. (2013). Analyzing Social Networks. London: Sage Publications Ltd.

Bracciale, R., y Martella, A, (2017). Define the populist political communication style: the case of Italian political leaders on Twitter. Information, Communication \& Society, 20(9), 1310-1329.

Brennen, B. S. (2013). Qualitative Research Methods for Media Studies. New York: Routledge.

Cammaerts, B. (2015). Neoliberalism and the Post-hegemonic War of Positions: The Dialectic Between the Invisibility and Visibilities. European Journal of Communication, 30(5), 522-538.

Casero-Ripollés, A.; Sintés-Olivella, M., y Franch, P. (2017). The Populist Political Communication Style in Action: Podemos' Issues and Functions on Twitter During the 2016 Spanish General Election. American Behavioral Scientist, 61(9), 986-1001.

Chadwick, A. (2007). Digital Network Repertories and Organizational Hybridity. Political Communication, 24(3), 283-301.

Chadwick, A. (2013). The Hybrid Media System. Politics and Power. 
New York: Oxford University Press.

Coleman, S. (2003). A tale of two houses: The Houses of Commons, the Big Brother house and the people at home. Parliamentary Afairs, 56(4), 733-758.

Colle, R. (2011). El análisis de contenido de las comunicaciones. Cuadernos Artesanos de Latina, 11, La Laguna, Tenerife: La Latina.

Couldry, N., y Hepp, A. (2013). Conceptualizing Mediatization: Context, Traditions, Arguments. Communication Theory, 23(3), 191-202.

Couldry, N. (2015). The myth of 'us': digital networks, political change and the production of collectivity. Information, Communication $\theta$ Society, 18(6), 608-626.

Couldry, N., y Hepp, A. (2017). The Mediated Construction of Reality. Cambridge: Polity Press.

Crossley, N., y Edwards, G. (2016). Cases, Mechanisms and the Real: Theory and Methodology of Mixed-Method Social Network Analysis. Sociological Research Online, 21(2), 1-15.

Deacon, D., y Stanyer, J. (2014). Mediatization: key concept or conceptual bandwagon?. Media, Culture \& Society, 36(7), 1032-1044.

della Porta, D., y Mattoni, A. (2014). Patterns of Diffusion and the Transnational Dimension of Protest in the Movements of the Crisis: An Introduction. En D. della Porta y A. Mattoni (Eds.), Spreading Protest. Social Movements in Times of Crisis (pp. 1-18). United Kingdom: ecpr Press.

della Porta, D., y Pavan, E. (2017). Repertoires of knowledge practices: social movements in times of crisis. Qualitative Research in Organizations and Management: An International Journal, 12(4), 291-314.

della Porta, D., Fernández, J., Kouki, H., y Mosca, L. (2017). Movement Parties Against Austerity. Cambridge: Polity Press.

Denzin, N. K. (1978). The research act: A theoretical introduction to sociological methods. New York: McGraw-Hill.

De Smet, B. (2016). Gramsci on Tahrir. London: Pluto Press. En D. della Porta, y M. Diani, (Eds.) Social Movements: An Introduction, 2nd Edition. London: Wiley.

de Vaus, D. (2001). Research Design in Social Research. Australia: SAGE.

Earl, J., y Kimport, K. (2009). Movement Societies and Digital Protest: Fan Activism and Other Nonpolitical Protest Online. Sociological Theory, (27), 220-43.

Edwards, G. y Crossley, N. (2009). Measures and Meanings: Exploring the Ego-Net of Helen Krikpatrick Watts, Militant Suffragette. Methodological Innovations Online, (4), 37-61.

Edwards, G. (2010). Mixed-Method Approaches to Social Network Analysis. Southampton: ESRC National Centre for Research Methods.

Entman, R. M. (2004). Projections of Power: Framing News, Public Opinion, and U. S. Foreign Policy. Chicago: University of Chicago Press.

Erikson, E. (2008). 'Hillary is my friend': MySpace and political fandom. Rocky mountain communication review, 4(2), pp. 3-16.

Feenstra, R., Tormey, S., Casero-Ripollés, A., y Keane, J. (2017). Refiguring Democracy. The Spanish Political Laboratory. New York: Routledge

Fenton, N., y Barassi, V. (2011). Alternative Media and Social Networking Sites: The Politics of Individuation and Political Participation. The Communication Review, 14(3), 179-196.
Flesher, C. M., y Montañés, A. (2014). Transnational Diffusion Across Time: The Adoption of the Argentinian Dirty War 'Escrache' in the Context of Spain's Housing Crisis. En D. della Porta y A. Mattoni (Eds.), Spreading Protest. Social Movements in Times of Crisis (19-41). United Kingdom: ecpr Press.

Flick, U. (2004). Introdución a la investigación cualitativa. Madrid: Morata.

Fontana, A., y Frey, J. (2005). The Interview, from neural stance to political involvement. En N. K. Denzin y S. Lincikn (Comp.), The Sage Handbook of Qualitative Research (pp. 695-727). London, UK: Sage.

Freelon, D. G. (2010). Analyzing online political discussion using three models of democratic communication. New Media \& Society, 12(7), $1172-1190$.

Freeman, L. C. (1979). Centrality in Social Networks. Conceptual Clarification. Social Networks, 1(3), 215-239.

García-Carretero, L., y Pérez-Altable, L. (2017). Barcelona en Comú on Twitter. Analyzing the electoral communication of the confluence during the 2015 council election. El Profesional de la Información, 26(5), pp. 871-883.

García-Carretero, L., y Codina, L. (2018). Visibilidad web y Comunicación política. Análisis de los sitios web de la confluencia Barcelona en Comú. VI Congreso Internacional de la AE-IC, Comunicación y Conocimiento, Salamanca: Universidad de Salamanca y AE-IC.

García-Carretero, L. y Díaz-Noci, J. (s/d). From social movements to political parties. Barcelona en Comú's electoral message, uses and limitations on Twitter during 2015 city council election. OBETS, Revista de Ciencias Sociales (en prensa).

Gitlin, T. (1980). The Whole World is Watching. Berkeley: University of California Press.

Goffman, E. (1986). Frame Analysis. An Essay on the Organization of Experience. Boston: Northeastern University Press.

Golafshani, N. (2003). Understanding reliability and validity in qualitative research. The Qualitative Report. Ontatio: University of Toronto.

Graham, T., Broersma, M., Hazelhoff, K., y van't Haar, G. (2013). Between Broadcasting Political Messages and Interacting with voters: The Use of Twitter during 2010 UK General Election. Information, Communication and Society, 16(5), 692-716.

Hallin, D. C. (2018). Mediatisation, Neoliberalism and Populism: the case of Trump. Journal of Academy of Social Science. DOI: $10.1080 / 21582041.2018 .1426404$

Jungherr, A. (2016). Twitter use in election campaigns: Systematic literature review. Journal of Information Technology \& Politics", 13(1), 72-91.

Kaillo, H., Pietilä, A-M., Johnson, M., y Kangasniemi, M. (2016). Systematic methodological review: developing a framework for a qualitative semi-structured interview guide. Journal of Advance Nursing, 72(12), 2954-2965.

Kane, G.C., Alavi, M., Labianca, G., y Borgatti, S. (2014). What's Different about Social Media Networks? A Framework and Research Agenda. MIS Quarterly, 38(1), 1- 30.

Kelly, S. E. (2010). Qualitative interviewing techniques and styles. En I. Bourgeault, R. Dingwall y R. De Vries (eds), The SAGE Handbook of Qualitative Methods in Health Research (pp. 307-327). London: Sage.

Klinger, U., y Svensson, J. (2015). The emergence of network media logic in political communication: A theoretical approach. New media 


\section{\& society, 17(8), 1241-1257.}

Krippendorff, K. (2013). Content Analysis. An introduction to its methodology. Los Ángeles: SAGE Publications.

Kvale, S. (1996). Interviews: An introduction to Qualitative Research Interviewing. London: Sage Publications.

Kvale, S. (2007). Doing interviews. Los Angeles: SAGE.

Lakoff, G. (2004). Don't Think of an Elephant!: Know your Values and Frame the Debate. Canada: Chelsea Green Publishing Company.

Landerer, N. (2013). Rethinking the Logics: A Conceptual Framework for the Mediatization of Politics. Communication Theory, 23(3), 239-258.

Lilleker, D. G., Koc-Michalska, K., y Schweitzer, E. J. (2011). Informing, engaging, mobilizing or interacting: Searching for a European model of web campaigning. European Journal of Communication, 26(3), 195-213.

Lilleker, Darren G., Tenscher, J., y Štětka, V. (2015). Towards hypermedia campaigning? Perceptions of new media's by party strategies in comparative perspective. Information, Communication \& Society, 18(7), 747-765.

Lobera, J. (2010). Sostenibilitat, participació i educació: les concepcions del món i de la tecnociència en la transformació dels conflictes socioambientals (Tesis Doctoral). Universidad Politécnica de Catalunya, Barcelona, España.

López-García, G., y Valera-Ordaz, L. (2015). El estudio de los flujos de comunicación en procesos de comunicación política: una aproximación metodológica. Recuperado de https://www.academia. edu/18288900/El_estudio_de_los_flujos_de_comunicaci\%C3\%B3n_ en_procesos_de_comunicaci\%C3\%B3n_pol\%C3\%ADtica_una_ aproximaci\%C3\%B3n_metodol\%C3\%B3gica

López-García, G. y Pavía, J. M. (2018). Political communication in election process: an overview. Contemporary Social Science DOI: 10.1080/21582041.2018.1479040

López-Noguero, F. (2002). El análisis de contenido como método de investigación. XXI Revista de Educación, (4), 167-179.

Madore, M. (2009). MySpace to your space: How celebrity politics and the Internet are transforming political communication among American youth. American communication journal, 11(1), 1-12.

Mazzoleni, G., y Schulz, W. (1999). "Mediatization" of Politics: A Challenge for Democracy?. Political Communication, 16(3), 247-261.

Mazzoleni, G. (2008). Mediatization of Politics. En W. Donsbach (Ed), The International Encyclopedia of Communication (pp. 3017-305). Malden, MA: Blackwell.

Mazzoleni, G. (2017). Changes in Contemporary Communication Ecosystems Ask For A "New Look" At The Concept of Mediatisation. Javnost-The Public, 24(2), 136-145.

McLuhan, M. (1987). El mensaje es el medio: un inventario de efectos. Barcelona: Paidós.

Mitchell, E. S. (1986). Multiple triangulation: A methodology for nursing science. Advances in Nursing Science, 8(3), 18-26.

Moffitt, B., y Tormey, S. (2014). Rethinking Populism: Politics, Mediatisation and Political Style. Political Studies, (62), 381-397.

Morrow, S. L. (2005). Quality and trustworthiness in qualitative research in counselling psychology. Journal of Counselling Psychology, 52(2), 250-260.
Mosca, L. (2014). The Five Star Movement: Exception or Vanguard in Europe?. The International Spectator. Italian Journal of International Affairs, 49(1), 36-52.

Olsen, W. K. (2004). Triangulation in Social Research: Qualitative and Quantitative Methos Can Really Be Mixed. En M. Holborn y Haralambos (Eds), Developments in Sociology (pp. 103-118). United Kindom: Causeway Press.

O'Sullivan, J. (2005). Delivering Ireland: journalism's search for a role online. Gazette, 67(1), 45-68.

Padovani, C. y Pavan, E. (2016). Global governance and ITCs: Exploring online governance networks around gender and media. Global networks, 16(3), 350-371.

Pavan, E. (2015). The cement of civil society. Foundations for a more genuine understanding of online collective action. Partecipazione $e$ conflitto, 8(3), 910-918.

Pavan, E. (2017). The integrative power of online collective action networks beyond protest. Exploring social media use in the process of institutionalization. Social Movement Studies, 16(4), 433-446.

Pérez-Altable, L. (2016). Social movements and network analysis: the case of Tunisian digital activism before and during the Arab Spring (2010-2011) (tesis doctoral). Universitat Pompeu Fabra, Barcelona, España.

Piccio, D. R. (2016). The impact of social movements on political parties. En L. Bosi, M. Giugni, y K. Uba (Eds.), The consequences of social movements (pp. 263-284). United Kingdom: Cambridge University Press.

Pietkiewicz, I. y Smith, J. A. (2014). A practical guide to using Interpretative Phenomenological Analysis in qualitative research psychology. Czasopismo Psychologiczne-Psychological Journal, 20(1), 7-14.

Poulakidakos, S. y Veneti, A. (2016). Political Communication and Twitter in Greece: Jumps on the Bandwagon or an Enhancement of the Political Dialogue? En T. Dezelan y I. Vobic (Eds.), (R)evolutionizing Political Communication through Social Media (pp. 119-146). USA: IGI Global.

Römmele, A., y von Scheneidmesser, D. (2016). Election campaigning enters a fourth phase: the mediatized campaign. $Z$ Politikwiss, (26), 425-442.

Ruiz-Olabuénaga, J. I. (2012). Teoría y práctica de la investigación cualitativa. Bilbao: Publicaciones de la Universidad de Deusto.

Sampedro, V. y Sánchez-Duarte, J. M. (2011). 15-M: La Red era la plaza. En V. Sampedro (Coord.), Cibercampaña. Cauces y diques para la participación, (pp. 237-242). Madrid: Universidad Complutense de Madrid.

Sanz, J., y Mateos, O. (2014). ¿No es país para jóvenes? Juventud, indignación y cambio social en el contexto post-15-M. Iglesia Viva, (258), 29-52.

Searle, J. R. (1976). Una taxonomía de los actos ilocucionarios. Teorema: revista internacional de filosofía, 6(1), 43-78.

Strömbäck, J. (2008). Four phases of mediatization: An analysis of the mediatization of politics. The International Journal of Press/Politics, 13(3), 228-246.

Tudoroiu, T. (2014). The Regional Foreign Policies of Black Sea "New Populist" Leaders. Debatte, 22(2), 161-180.

Valera-Ordaz, L. (2018). Conversaciones políticas en Facebook. Explorando el papel de la homofilia en la argumentación y la interacción 
comunicativa. Revista Latina de Comunicación Social, 73, 55-73.

Van Gorp, B. (2010). Strategies to Take Subjectivity Out of Framing Analysis. En P. D'Angelo y J. A. Kuypers (Ed.), Doing News Framing Analysis. Empirical and Theoretical Perspectives (pp. 84-109). New York: Routledge.

Webb, E. J., Campbell, D. T., Schwartz R. D., y Secherest, L. (1966). Unobtrusive measures: Non-reactive research in the social sciences. Chicago: Rand McNally.

Wengraf, T. (2001). Qualitative Research Interviewing: Biographic Narrative and Semi-structured Methods. London: SAGE.

Wimmer, R. y Dominick, J. (1996). La investigación científica en los medios de comunicación. Una introducción a sus métodos. Barcelona: Boch.

Wimmer, R. y Dominick, J. (2011). Mass Media Research: an Introduction. Boston: Wadsworth.

Wolton, D. (1989). La communication politique: construction d'un modèle. Hermès, (4), 27-42.

Yin, R. K. (2009). Case study research: Design and methods (4th Edition). Thousand Oaks: Sage.

\section{CV}

Lucía García-Carretero. Investigadora pre-doctoral en el Grupo de Investigación en Documentación Digital y Comunicación Interactiva (DIGIDOC) y en el Grupo de Investigación en Periodismo (GRP) del Departamento de Comunicación de la Universitat Pompeu Fabra. Graduada en Periodismo por la Universidad de Valladolid y máster en Comunicación Social en la Universitat Pompeu Fabra. Sus principales líneas de investigación son la comunicación política, el periodismo en Internet y los medios sociales como herramienta comunicativa.

\section{ocm Observatorio deCibermedios}

\section{https://observatoriocibermedios.upf.edu/}

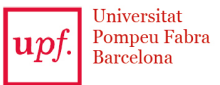

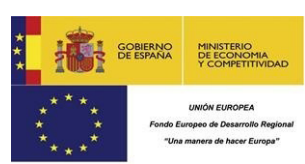

El Observatorio de Cibermedios es una producción del Grupo de Investigación en Documentación Digital y Comunicación Interactiva (DigiDoc) del Departamento de Comunicación de la Universitat Pompeu Fabra.

El Observatorio de Cibermedios (OCM) forma parte del proyecto del Plan Nacional "Creación y contenido interactivo en la comunicación de información audiovisual: audiencias, diseño, sistemas y formatos". CSO2015-64955-C4-2-R (MINECO/ FEDER), Ministerio de Economía y Competitividad (España). 